\title{
MONTAIGNE E A NATUREZA HUMANA NO FEMININO
}

\author{
Maria Célia da Veiga França* \\ lelavfranca@yahoo.com.br
}

RESUMO Partindo de algumas passagens dos Ensaios de Montaigne, e, especialmente, do capítulo "Sobre versos de Virgílio", consideramos o retrato da mulher elaborado pelo autor. Contrariamente à maioria dos autores de sua época - dentre os quais Bodin e Charron que, seguindo Aristóteles, consideram que a mulher possui uma natureza inferior à do homem, feita para obedecer, enquanto este último o foi para governar -, Montaigne nos apresenta outro quadro. Influenciado, acreditamos, pelo texto de Agrippa sobre as mulheres, ele propõe uma igualdade dos gêneros desequilibrada, perturbada e aniquilada tanto pela tradição quanto pelos costumes.

Palavras-chave Mulher, natureza humana, costumes, Agrippa.

ABSTRACT Taking as a starting point some passages of Montaigne's Essays and the chapter "On some verses of Virgil", we consider the woman's portrait composed by the author. In contradicion with the majority of his contemporary authors - such as Bodin and Charron who, in accordance with Aristotle, consider women's nature as inferior to that of men, since women are meant to obey while men are meant to rule -, Montaigne presents us another picture. Influenced by, we believe, Agrippa's text on women, he proposes an equality between the genders unballanced, perturbed and annihilated by both tradition and customs.

Keywords Woman, human nature, habits, Agrippa.

* Doutora pela Universidade Caen- Normandie. Artigo recebido em 31/5/2012 e aprovado em 05/08/2012. 
Debruçar-se sobre a questão da natureza humana em Montaigne é um empreendimento arriscado e difícil. Assim como não esperaríamos tirar uma definição da natureza humana dos Ensaios, também não esperaremos tirar uma definição da natureza ou essência da mulher. Todavia, encontramos passagens que esclarecem o que ele entende por mulher e qual acredita ser seu papel no mundo: acreditamos desta forma poder, sim, vislumbrar sua natureza. É verdade que ele abre espaço para algumas mulheres virtuosas em sua obra; porém, no geral, a visão feminina apresentada por ele no texto tende a ser bastante misógina e conservadora, seguindo a tradição renascentista, ao afirmar a inadequação da mulher, por exemplo, para os estudos, assim como seu lugar de submissão junto ao marido. Esta visão e o apagamento da mulher é de tal forma comum em seu tempo, que elas apenas são mencionadas em textos (sejam eles sobre política, biologia ou filosofia...) referentes ao casamento.

Em Montaigne não é muito diferente, tanto é que um dos capítulos em que ela se torna mais presente é o "Sobre versos de Virgílio", onde ele fala longamente sobre sexo, sobre amor e sobre casamento. Para tentar esboçar o que nosso autor entende por natureza da mulher, vamos nos limitar praticamente a este capítulo; não trabalharemos o texto como um todo e deixaremos a questão do casamento de lado, para analisar mais detalhadamente algumas pequenas passagens e, sobretudo, as últimas linhas do capítulo mencionado. Todavia, antes de tratarmos do texto dos Ensaios propriamente dito, passaremos por trechos de autores contemporâneos de Montaigne, na tentativa de esboçar o que estes entendiam, em sua maioria, pela natureza da mulher.

Começaremos nosso percurso com algumas passagens de Jean Bodin, que apresenta, como poderemos ver, uma opinião amplamente compartilhada neste período. No capítulo 5 do sexto livro da República, ele afirma que:

"a Monarquia deve ser destinada unicamente aos machos, dado que a Ginecocracia é diretamente contra as leis da natureza que deu aos homens a força, as armas, o comando e a tirou das mulheres: e a lei de Deus ordena eloquentemente que a mulher seja submissa ao homem, não somente quanto ao governo dos reinos e impérios, mas também quanto à família de cada um em particular. E até mesmo a lei proibiu à mulher qualquer cargo e serviço próprios aos homens, como o julgar, o postular e outras coisas semelhantes: e isto não somente por falta de julgamento, mas também porque as ações viris são contrárias ao sexo, e ao pudor e castidade femininas"'.

Essa submissão e incapacidade têm sua causa explicitada em uma passagem do primeiro livro da República, com o estabelecimento e a justificativa do poder marital. A família, fundamento da república, não poderia 
existir sem a mulher. Esta é, portanto, necessária e fundamental, mas nem por isto semelhante ao homem. Remetendo-se com frequência a Aristóteles, Bodin sugere que a manutenção da república depende da preservação da família, que depende do saber comandar bem, obviamente masculino. O homem livre só pode ser comandado pela razão, que tem conformidade com a vontade divina. Portanto, "o mais antigo comando é aquele da razão sobre o apetite animal"2, comando que ele transferirá para o homem, representante da razão, sobre a mulher, representante do apetite animal. O comando que Deus deu ao homem sobre a mulher tem "dois sentidos e dois comandos: o literal, do poder marital; e o moral, da alma sobre o corpo e da razão sobre a concupiscência, que a santa Escritura chama quase sempre de mulher"3.

Neste ponto específico, ou seja, relativamente à diferença entre o homem e a mulher e a consequente submissão desta ao homem, Bodin parece seguir bastante de perto as proposições de Aristóteles. Esperamos conseguir mostrar, ao longo deste texto, o quanto a leitura de Montaigne diverge destes dois autores. Mais ainda, esperamos também apontar para mais uma tese do aristotelismo que, ainda que de forma não explícita, é rejeitada pelos Ensaios: a da natureza específica da mulher, somada à da natureza humana desconstruída na "Apologia".

Retomemos, rapidamente, alguns pontos da Política aristotélica. A relação entre o homem e a mulher é necessária para a república, assim como, em menor grau, a relação entre o homem livre e seu escravo. Em 1254b 12 ele afirma: "também entre os sexos, o macho é por natureza superior e a fêmea inferior, o macho governador e a fêmea subjugada", isto porque aquele é naturalmente mais adequado para o comando. Diferentemente do escravo, que não possui a parte deliberativa da alma, a mulher a possui, mas em menor grau do que o homem. Aquele que tem o comando deve possuir a virtude intelectual em sua completude, o que não é o caso da mulher, que pode, sim, possuir virtudes, mas adequadas a seu papel de subordinação. Aristóteles termina sua argumentação a respeito da inferioridade da mulher, afirmando 4 que a virtude moral, a temperança, a coragem e a justiça que homens e mulheres possuem não podem ser as mesmas, concluindo com o exemplo de que a coragem de um é a do comando e a coragem de outro é a da submissão. Por fim, refuta explicitamente Sócrates, que teria sustentado a tese da igualdade da coragem ou da justiça, ou seja, da virtude, de um e outro. 
Enquanto alguns autores recorrem à filosofia, notadamente a Aristóteles, para afirmar a diferença natural existente entre homens e mulheres, partindo daí para justificar o comando daqueles e a submissão delas, como aconteceu claramente no caso de Bodin, outros lançam mão da tradição bíblica para a obtenção de provas que os levem às mesmas conclusões. É o caso, por exemplo, de Charron, no capítulo sobre o casamento do livro I do $D a$ Sabedoria. Mantendo a tradição, este autor também falará da natureza da mulher no capítulo sobre o casamento, capítulo este que se encontra entre os capítulos "Sobre o comando e a obediência", "Sobre pais e filhos" e "Sobre senhores e escravos", fazendo com que o desenvolvimento da temática se assemelhe bastante àqueles propostos por Bodin e por Aristóteles.

A distinção entre superioridade e inferioridade, nos diz então Charron, consiste no fato de que o marido tem poder sobre a mulher e a mulher é sujeita ao marido, segundo todas as leis e governos. Esta superioridade e esta inferioridade são naturais, pois se encontram fundamentadas na força e na suficiência de um, na fraqueza e insuficiência do outro. Os teólogos a fundamentam ainda sobre outras razões, tiradas da Bíblia. São elas o fato de que o homem foi feito por Deus primeiramente e sozinho, imediata e deliberadamente, para Deus e à sua imagem. Neste sentido ele deve ser perfeito, já que a natureza começa sempre pela coisa perfeita. Quanto à mulher, ela foi feita com a substância do homem, em segundo lugar, depois dele, por acaso e com outra finalidade, ou seja, para servir de ajuda e de companhia para o homem seu chefe. Esta é a razão de sua imperfeição, baseada na ordem da geração. A ordem da corrupção e do pecado servem para trazer a mesma prova. A mulher foi a primeira em prevaricação, e por sua própria autoridade pecou. O homem pecou em segundo lugar, por causa da mulher. A mulher então foi última quanto ao bem e também quanto à geração, mas primeira a provocar o mal e ainda foi o motivo dele. É, portanto, com justiça que ela deve ser sujeitada ao homem, que foi o primeiro no bem e último no mal5.

As passagens dos textos de Bodin e de Charron ilustram, de forma bastante reveladora, a leitura da natureza e do perfil da mulher feita pela maioria dos autores contemporâneos de Montaigne. Podemos resumir essa leitura em uma tese, dizendo que se trata de um ser humano por natureza inferior; ligado à luxúria e não à razão; criado para cuidar do lar, para viver submisso e para obedecer ao homem (seja ele o pai no caso da infância, seja ele o marido, quando na puberdade). Podemos dizer que Montaigne acompanha sua época 
no que diz respeito à aceitação de alguns desses elementos, como, por exemplo, o fato de a mulher ser considerada mais dada e suscetível à luxúria do que o homem. No próprio capítulo "Sobre versos de Virgílio", Montaigne afirma que seria loucura tentar refrear o desejo sexual nas mulheres, uma vez que este é lancinante e natural nelas ${ }^{6}$.

Quanto ao papel que a mulher deve exercer na sociedade e em sua casa, parece-nos bastante claro que Montaigne também assume uma posição conservadora, ou tradicional. Saindo um pouco do capítulo "Sobre versos de Virgílio" para o capítulo "Da vaidade", por exemplo, encontramos uma definição expressa do papel que Montaigne atribui à mulher:

[B] A mais útil e honrosa ciência e ocupação para uma mulher é a ciência da administração dos bens. Vejo alguma avarenta; boas administradoras, muito poucas. É sua qualidade mestra, e que devemos procurar antes de qualquer outra, como o único dote que serve para arruinar ou salvar nossas casas. [C] Sem discussão: de acordo com o que a experiência me ensinou, de uma mulher casada exijo, acima de qualquer outra virtude, a virtude administrativa (III, 9, 975/284-285).

Caberia aqui perguntarmo-nos se esta ciência administrativa ou a responsabilidade incumbida à mulher podem ser ditas equivalentes à subordinação, inferioridade ou incapacidade atestadas pelos autores anteriores. Continuando a citação, ele faz uma referência à experiência pessoal com sua mulher, afirmando em [B]:

Coloco-a à altura disso, deixando-lhe nas mãos, com minha ausência, todo o governo. Vejo com irritação em muitos lares o cavalheiro retornar aborrecido e em frangalhos da azáfama de seus negócios, por volta de meio-dia, e eis que a dama ainda está se penteando e se adornando em sua alcova (III, 9, 975/284-285).

A ação de deixar o governo nas mãos de sua mulher, ainda que seja o governo da casa (e da educação de sua filha, como veremos posteriormente), parece indicar a atribuição de uma capacidade bem mais ampla do que vimos até então. Apesar de tudo, Montaigne já se distancia um tanto das teses apresentadas anteriormente. Com efeito, previamente a mulher tinha um papel totalmente passivo na relação familiar estabelecida, enquanto ela parece ter, no caso proposto por nosso autor, uma função já um tanto quanto ativa - ainda que restrita e bem delimitada pelo homem.

6 Ver III, 5, 866/120-121. Citamos os Ensaios consultando a tradução de Rosemary Costhek Abílio (Editora Martins Fontes) e modificando-a eventualmente. As referências trazem, em algarismos romanos, o número do livro e, em algarismos arábicos, em sequência, o número do capítulo, da página da Edição Villey (PUF) e da página da tradução brasileira. 
É interessante ressaltarmos ainda a ausência, seja no "Sobre versos de Virgílio", seja no "Da Vaidade" (dois capítulos que abordam mais diretamente a questão do papel da mulher), de alguns elementos que normalmente acompanham a discussão. São eles: o estabelecimento da família como necessária à boa manutenção da sociedade, e o poder marital, situado dentro do quadro mais geral das diferentes relações de comando e obediência, onde encontramos também a relação senhor-escravo. Como vimos anteriormente, esta é a estrutura desenvolvida por Aristóteles e seguida por muitos dos autores do Renascimento.

$\mathrm{Na}$ medida em que o desenvolvimento teórico no qual encontramos a mulher é muito homogêneo neste período, e estruturado de forma bastante semelhante ao da Política, e na medida ainda em que é possível identificar alguns desvios por parte de Montaigne no que se refere a este esquema, traremos a leitura de outro autor, que foi seu contemporâneo e a quem ele conhecia, responsável por uma tese totalmente revolucionária sobre a natureza da mulher. No paralelo estabelecido entre o pensamento tradicional e o texto Da excelência e da nobreza da mulher, de Cornelius Agrippa, buscaremos situar o lugar de Montaigne ${ }^{7}$. Para sua demonstração, o alemão se apoia principalmente nos textos bíblicos, recorrendo também algumas vezes aos filósofos antigos. É interessante notar que, enquanto Bodin se apoiava em Aristóteles para construir sua argumentação, Agrippa recusa explicitamente a filosofia deste autor, recorrendo por sua vez a Platão e a Santo Agostinho.

Buscaremos fazer uma pequena recapitulação desse texto, que é pouco divulgado, trazendo os elementos principais da argumentação do autor. Ele

7 Gostaríamos de agradecer a preciosa sugestão de leitura feita pelo professor Luiz Eva durante o Colóquio Montaigne: Novas Leituras, ao apontar para o paradoxo como uma importante chave de leitura para os textos de Agrippa e de Montaigne utilizados aqui. Apesar de não termos ainda começado um trabalho com esta chave de interpretação, gostaríamos de salientar que, no que diz respeito ao texto de Agrippa, esta nos parece muito plausível. Em um primeiro momento, todavia, não temos a mesma clareza no que diz respeito ao texto de Montaigne. A presença e a utilização do paradoxo nos Ensaios, trabalhada de forma minuciosa pelo professor Eva em A figura do filósofo, nos parece acontecer sobretudo em textos onde encontramos uma reflexão sobre o ceticismo e a questão do conhecimento. Momentos em que Montaigne emprega o paradoxo "como um instrumento destinado a conduzir o leitor a julgar por si mesmo, ante o efeito desconcertante dos elementos dispostos" (A figura do filósofo, p. 227), se serve dele "como instrumento para conduzir o leitor à boa atividade filosófica, tal como a preconiza e busca pôr em prática" (Idem, p. 240) e deseja "levar à dúvida cética em seu sentido filosófico próprio, encaminhando o juízo numa investigação em cujo horizonte se projeta a perspectiva de reconhecimento da incapacidade de escolher entre as filosofias que prometem a verdade" (Idem, p. 243). O que está em jogo na reflexão sobre as mulheres, assim como na reflexão sobre os indígenas e tantos "outros" de Montaigne, nos parece ser outra coisa. Acreditamos que se trate de uma opinião já consolidada, que ele não coloca em discussão, ainda mais por se tratar de temas tão envolvidos com a moral. O texto de Agrippa, repleto de ironias e exageros, provavelmente escrito como discurso paradoxal, parece-nos ter influenciado o texto de Montaigne não por sua forma, mas por seu conteúdo, que o francês retoma de forma grave e livre de ironias. 
começa seu texto fazendo uso da religião para mostrar que Deus criou o homem macho e fêmea com diferenças em suas naturezas que se limitam às partes do corpo relacionadas à procriação. No mais, distribuiu uma mesma forma de alma ao macho e à fêmea; a mulher possui, portanto, o mesmo sentido, o mesmo entendimento, a mesma razão e a mesma palavra que o homem, tendendo ainda ao mesmo fim de beatitude e de felicidade que ele ${ }^{8}$. No que diz respeito à essência e à substância espiritual, e este ponto é fundamental, não pode, dessa maneira, existir nenhuma preeminência de nobreza entre eles. Mais ainda, segundo Agrippa, receberam uma liberdade igual e justa. Quanto à natureza, assim, parecem ter recebido o mesmo lote, mas quanto ao resto, Agrippa parece atribuir uma melhor fortuna à mulher. Seria, por exemplo, o caso do nome, que a mulher recebeu melhor do que o homem, pois Adão significa terra, enquanto Eva significa vida.

Quanto à ordem da criação, que já havia sido mencionada por Charron em sentido oposto, Agrippa afirma que a mulher foi criada por último para concluir com perfeição a ordem do mundo. Tanto é assim que depois de criála, Deus repousou, finalizando com ela a obra em que colocou e conformou toda a sua sabedoria e poder. Sendo a mulher a última das criaturas colocada no mundo, o fim e o cumprimento mais perfeito das obras de Deus e perfeição do universo, dentre as criaturas, deve também ser a mais digna em nobreza e grandeza, pois sem ela o mundo seria imperfeito. Deus não terminaria uma obra tão grandiosa com uma coisa não perfeita. O que também pode ser demonstrado pela filosofia, que afirma que o fim é o primeiro em intenção, mas o último em execução9 . Invertendo mais ainda os papéis, Agrippa sugere que todas as outras criaturas deveriam amá-la, honrá-la, obedecer-lhe e tornaremse escravas da rainha das criaturas.

No que diz respeito à matéria da criação, também a mulher parece sobressair-se, uma vez que o homem, como todos os outros seres e animais, foi criado do lodo e da lama, enquanto a mulher foi criada de uma matéria purificada, vivificada, animada, racional e participante do entendimento divino $^{10}$. Ou seja, a mulher é obra de Deus, enquanto o homem obra da Natureza. Agrippa estabelece então uma diferença significativa, uma vez que atribui à mulher uma maior capacidade para receber a luz divina do que o homem, retrato, segundo ele, de sua pureza e beleza. Da pureza e beleza da mulher ele conclui uma honestidade oposta à luxúria realçada pelos outros 
autores. Somemos a isto o fato de que a mulher foi escolhida para a procriação do gênero humano ${ }^{11}$. Somemos ainda o dado importantíssimo de que não foi pecadora como Adão, porque o fruto da árvore do conhecimento tinha sido proibido ao homem e não à mulher, que ainda não tinha sido criada. $\mathrm{O}$ pai pecou e carregou a morte, não ela que caiu em erro por ignorância. Da mesma forma que o diabo a tentou por ser ela a mais excelente dentre as criaturas, também Jesus ressuscitado dos mortos apareceu primeiramente às mulheres e não aos homens, que abandonaram sua fé. Agrippa procura então provar, na sequência, a importância das mulheres para a sobrevivência do cristianismo, contra o qual elas nunca se revoltaram, não tendo sido heréticas nem idólatras. Além disso, a traição, acusação, condenação, crucificação e morte de Jesus foram obras masculinas e não femininas ${ }^{12}$.

Passemos a um outro aspecto crucial, a refutação de Aristóteles, segundo o qual os machos são os mais fortes entre os animais, os mais sábios e os mais nobres. Agrippa se dirige a São Paulo, que responde ao filósofo grego que Deus tomou e escolheu o louco, para confundir o sábio; o fraco, para derrubar o forte e o desprezado, para rebaixar quem não o era. Esta inversão chega ao ponto de mostrar que muitas vezes, nos textos sagrados, a iniquidade da mulher é mais abençoada e louvada do que a bondade dos homens ${ }^{13}$. Retomando um outro argumento de Aristóteles para provar a excelência da mulher, ele lembra que "o gênero do qual a excelência é mais nobre do que a de um outro, é ele também mais nobre que o outro". Ora, a virgem Maria, a melhor do gênero feminino, é mais excelente do que São João, o melhor do gênero masculino.

Agrippa fecha esta prova da excelência, bondade e inocência femininas afirmando que todos os males vieram dos homens, não das mulheres. $\mathrm{O}$ primeiro homem criado foi quem violou as regras do Senhor, fechando as portas do céu para sua posteridade; o primeiro invejoso, o primeiro homicida, o primeiro parricida. Lamech foi o primeiro a ter mulheres; Noé o primeiro que se embebedou e Nemrod o primeiro tirano e idólatra. O homem foi o primeiro adúltero, o primeiro incestuoso, o primeiro a estabelecer uma aliança com o diabo e o primeiro a apresentar volúpia contra a natureza (em Sodoma e Gomorra).

Ele acrescenta então que, se tivesse sido dada às mulheres a permissão de fazer leis e de escrever histórias, estas teriam criado tragédias sanguinolentas inspiradas na malícia dos homens, que são assassinos, ladrões, sequestradores, 
falsários e traidores. Enquanto isto as mulheres foram as inventoras das artes liberais, das virtudes e dos bens; tanto é que as artes e virtudes possuem nomes femininos, assim como as diferentes regiões da terra tais a Ásia, a África, a Europa, a Líbia... Além do mais, ela foi a primeira a dedicar sua virgindade a Deus, e as profetisas sempre foram mais inspiradas pelo Espírito Santo. Sem contar sua constância, paciência, desprezo pela morte, determinação e resolução, todos testemunhados pelas santas escrituras ${ }^{14}$. Neste sexo altamente devoto, reluz, segundo o autor alemão, a fé universal, e nele ainda permanecem as obras de piedade. Voltemos rapidamente a Montaigne para lembrar que este é um ponto com o qual o autor certamente estaria de acordo, uma vez que ele apresenta, ao longo de todos os Ensaios, inúmeras histórias, exemplos e até mesmo anedotas, testemunhando a constância, a paciência e o desprezo pela morte em mulheres da antiguidade, dos textos bíblicos, mas também das contemporâneas, como no caso das judias portuguesas e das americanas.

Para que não permaneçam dúvidas sobre a igual capacidade entre umas e outros, Agrippa afirma que, não fosse a interdição às mulheres de aprenderem as letras, estas ultrapassariam os homens em saber e em grandeza de espírito. Com o meio exclusivo de seu natural já superam os grandes mestres das disciplinas; assim como as mães e amas-de-leite ensinam melhor o falar bem do que os gramáticos; assim como os aritméticos não enganam uma mulher ao pagar uma conta; nem o músico torna um canto tão agradável e gracioso; nem os filósofos, os matemáticos e os astrólogos se mostram superiores às adivinhações e conhecimentos das mulheres dos campos; ou os médicos fazem melhor do que certas velhas ${ }^{15}$.

Apesar de as mulheres do Renascimento terem sido afastadas da vida pública e consideradas incompetentes em termos de política, Agrippa desenvolve uma argumentação na sequência de seu texto com inúmeros exemplos, sobretudo antigos, da habilidade feminina neste âmbito. Existiram mulheres com grande prudência e de grande nobreza que, com sua coragem e virtude, salvaram seus países $^{16}$, assim como salvam e preservam, além de suas famílias e repúblicas, todo o gênero humano. Por todas estas razões foram honradas pelos primeiros reis persas e romanos, mas, sobretudo, pelo controverso Justiniano, que abriu grande espaço para sua mulher em seu governo, tomando sua opinião na elaboração de suas leis. Não é à toa que os grandes legisladores, que foram 
Platão e Licurgo ${ }^{17}$, decretaram que as mulheres não perdem para os homens em excelência de espírito, em força física nem em dignidade natural. Em consequência, ordenaram que elas se exercessem, assim como os homens, nas lutas, exercícios e coisas pertencentes à disciplina da guerra.

Agrippa acrescenta ainda alguns exemplos de povos antigos (como os citas, os trácios ou os gauleses) entre os quais os homens eram por costume moles e desocupados, enquanto as mulheres aravam os campos, edificavam, comercializavam, cavalgavam, guerreavam, eram chamadas para tratar da guerra e da paz, e faziam tudo aquilo que séculos depois lhes seria proibido fazer. Nos dias de hoje, nos diz o alemão, a liberdade usufruída por aquelas mulheres foi reprimida pela tirania dos homens, que se voltam contra o direito e as leis da natureza. Agora, diz ele, as leis pró́bem sua liberdade; o costume e os usos a eliminam, a educação a apaga e aniquila. Isto porque desde o seu nascimento, a mulher é contida em uma indolência que não lhe permite fazer mais do que cuidar de seu fio e de sua agulha, como se não fosse capaz de manejar e conduzir cargos mais altos e importantes. E assim que atinge a idade de quinze anos, é entregue ao comando ciumento de um marido ou fechada nas paredes de um claustro de religiosas ${ }^{18}$. Uma vez proibido seu acesso aos serviços públicos, todas as ações jurídicas lhes são obviamente negadas, assim como procurações, tutelas e participação em negócios testamentários e criminais.

A malícia dos fazedores de leis é tão grande, nos diz ele, que vão contra as escrituras e a vontade divina, recusando também a participação delas no púlpito da palavra de Deus, porque as escrituras diziam: suas filhas profetizarão assim como ensinavam no tempo dos apóstolos ${ }^{19}$. Aqueles maliciosos não levaram em conta o comando de Deus, e estabeleceram tradições nas quais as mulheres valiam menos do que os homens, mesmo tendo consciência do contrário. Essas tradições estabeleceram leis que as mulheres foram obrigadas a obedecer, segundo ele como pobres cativas de guerra sob seus vencedores. Nada disso, portanto, é estabelecido por necessidade, por razão divina ou natural, mas por um costume, uma educação, um acaso e uma oportunidade tirânicas. Notemos rapidamente que, na passagem final de "Sobre versos de Virgílio", ao afirmar ele também que a diferença entre homens e mulheres não é natural, mas estabelecida, Montaigne utiliza termos muito próximos dos de Agrippa, dizendo que a educação e o costume são responsáveis por essa diferença. 
$\mathrm{Na}$ sequência de uma passagem em que Montaigne tenta estabelecer as diferenças entre o amor e o casamento, escrita basicamente na camada [B]; e na sequência ainda a um pequeno acréscimo em [C], em que faz menção aos dois legisladores apontados por Agrippa como sendo aqueles que estabeleceram a igualdade entre os sexos em suas repúblicas, que são Licurgo e Platão, o francês faz uma observação muito interessante no que diz respeito às regras sociais:

As mulheres têm razão ao recusar as regras da vida introduzidas no mundo, ainda mais que foram os homens que as criaram sem elas. Existe naturalmente uma rixa e uma disputa entre as mulheres e os homens, até mesmo o maior acordo entre uns e outros é tempestivo e perturbado (III, 5, 854/103).

Além de demonstrar a abertura de espírito de nosso autor, concordando com a liberdade das mulheres de recusar regras que lhe foram impostas, este trecho lembra ainda a argumentação final de Agrippa. Com efeito, este último nos diz, ao fim de sua obra, que na medida em que tiveram sua liberdade natural tolhida, e que sofreram a imposição de uma educação e de um costume que as submeteram ao homem e as colocaram em um lugar de inferioridade e de incompetência, estas podem, sim, julgar esta imposição.

Continuando tal reflexão, Montaigne acompanha mais uma vez Agrippa ao apontar para o objetivo imposto às mulheres pela sociedade. Agrippa já dizia que, uma vez tolhida sua liberdade, a mulher era confinada à inatividade e sua ocupação limitada à costura. Montaigne, que parece mais fazer uma constatação do que um julgamento de valor como Agrippa, afirma que elas são tratadas desde a infância em função daquilo que diz respeito ao amor ou, melhor dizendo, à conquista e ao casamento: “[B] Sua graça, vestimenta, ciência, palavra e instrução visam este fim” (III, 5, 856/106).

Por fim, a condição de esposa - como única acessível à mulher - já está tão enraizada que as próprias mulheres, salienta Montaigne, na medida em que se ocupam da educação das moças, fazem do casamento o fim de sua criação. Registramos, como curiosidade, que na sequência do texto ele acrescenta ainda que sua filha, na época já com uma idade considerada apta para o casamento, não parece estar pronta para tal passagem, porque teve uma educação isolada e particular por parte de sua mãe e, contrariamente ao comum, ainda não tinha se desembaraçado da ingenuidade da infância. E comenta um pouco mais à frente (III, 5, 884/148) que a austeridade na educação das moças não oferece o resultado almejado, e que em sua época elas são preparadas com segurança, enquanto em outras gerações eram preparadas pelo medo e pela vergonha.

Tendo sido visualizado o quadro mais geral sobre a mulher, ainda que de forma rápida, assim como tendo sido visualizados alguns elementos do 
texto de Montaigne que nos permitem aproximá-lo de uma ou outra tendência, podemos finalmente abordar as últimas linhas do capítulo "Sobre versos de Virgílio", onde acreditamos encontrar uma resposta mais concreta para sua "filiação". Na camada [B] ele escreve: "Digo que os homens e as mulheres são feitos no mesmo molde: exceto a educação e os usos, a diferença não é grande". Passando para a camada [C], ele continua:

Platão convida indiferentemente uns e outras para a participação em todos os estudos, exercícios, cargos, profissões da guerra e da paz, em sua república; e o filósofo Antístenes suprimia qualquer distinção entre a virtude delas e a nossa. [B] É muito mais fácil acusar um sexo do que escusar o outro (III, 5, 897/168).

Lembremos que Agrippa também utiliza a mesma metáfora, afirmando que são feitos na mesma forma.

Platão, citado pelo francês e pelo alemão, e aprovado por ambos no que diz respeito à sua visão sobre a mulher, introduz essa questão em meio a uma reflexão sobre o Estado, já que se trata do livro A República, mais especificamente após discutir a questão da virtude e da justiça, juntamente com o problema da educação das crianças. A diferença entre ele e Aristóteles aparece já na organização do texto: enquanto o estagirita anuncia a natureza menor da mulher, apresentando-a no capítulo sobre o comandar e o obedecer ao lado dos escravos e crianças, o ateniense aponta para sua igualdade, mencionando-a em seguida a uma discussão sobre a necessidade da virtude para o cidadão. Além disso, enquanto afirma que homens e mulheres devem receber a mesma educação para estarem aptos a exercer as mesmas tarefas, ele sustenta ainda ${ }^{20}$, com o exemplo de mulheres fazendo ginástica junto aos homens, que esta prática poderia parecer risível para alguns, porque a tradição enraizou o costume contrário. Trata-se, portanto, de um costume a ser superado, e não de uma regra estabelecida pela natureza. Montaigne e Agrippa também apresentam o lugar da mulher estabelecido pela tradição, não pela natureza.

Assim, no que diz respeito à tese da diferença de natureza entre o homem e a mulher, já mencionada como amplamente aceita pelos autores renascentistas, Montaigne se distancia claramente de sua época, propondo a ideia bastante radical da igualdade de natureza entre os gêneros feminino e masculino. Fica manifesto, sobretudo nestas últimas linhas do capítulo, que o francês apresenta importantes semelhanças com passagens encontradas na 
obra de Cornelius Agrippa. Ainda que não constando no catálogo dos livros de Montaigne, como no caso da Filosofia oculta e da Incerteza e vaidade das ciências, acreditamos que esta obra, escrita em latim em 1509, poderia ter sido lida por ele e ter exercido influências sobre o pensamento de nosso autor.

Fechando este trabalho, é o momento de tentar fazer um resgate do percurso empreendido. Primeiramente, é bom lembrar que, em muitos aspectos, Montaigne não se desliga totalmente da visão predominante $\mathrm{e}$ conservadora sobre a mulher de sua época. Não obstante, alguns pontos de clara distinção podem ser destacados. Comecemos pela recusa da definição da natureza da mulher como uma menor racionalidade, face à racionalidade plena da natureza do homem que, diga-se de passagem, ele também recusa. Segundo ponto, homens e mulheres possuem diferenças físicas e morfológicas dadas as necessidades de reprodução da espécie, mas sua natureza é a mesma, ainda que não definível. Isto significa afirmar uma igualdade de ambos quanto ao entendimento, à virtude, às capacidades e às finalidades. Montaigne abraça, portanto, Platão para recusar Aristóteles. Último ponto, o papel atribuído à mulher em sua sociedade é arbitrário, porque imposto pela tradição masculina. Ainda que não se trate de uma definição, estes traços nos permitem ter uma boa visão da mulher pintada pelos Ensaios.

\section{Referências bibliográficas}

AGRIPPA, Henri-Corneille. De l'excellence et de la superioritéde la femme. Trad. François Peyrard. Paris: Louis, 1801. De nobilitate et prcecellentia feminei sexes [1509].

ARISTÓTELES. Politics. Trad. de H. Rackham. Londres: Loeb Classical Library, 2005.

BODIN, Jean. Les six livres de la république. Vol. 6. Paris : Fayard, 1986. [1576].

CHARRON, Pierre. De la Sagesse. Paris: Fayard, 1986. [1601].

MONTAIGNE, Michel. Les Essais. PUF: Paris, 2004. [1595].

MONTAIGNE, M. Os Ensaios. Trad. Rosemary C. Abílio. São Paulo: Martins Fontes, 2000.

PLATÃO. République. Bibliothèque de la Pléiade. Tradução e notas de Léon Robin com a colaboração de M.-J. Moreau, Paris : Gallimard, 1950. 